\title{
PANDANGAN AKTIVIS HIZBUT TAHRIR INDONESIA (HTI) DI MALANG TENTANG METODE IJTIHAD HTI DALAM BIDANG POLITIK DAN IBADAH
}

\author{
Fadh Ahmad Arifan \\ UIN Maulana Malik Ibahim Malang \\ Email:fadh_arif@yahoo.co.id
}

\begin{abstract}
Abstrak
This research examines the views of HTI activists Malang to the methods of ijtihad in the field of politics and Worship. By using qualitative method and interview, the research concludes that HTI's method of ijtihad in the field of political activists beginning with fahmul waqi 'and fahmul nash as well a methods formulated bt HT (ijtihad manhaji). If the problem is quite old, they take reference in the books of HT such as the Islamic system of Islamic government and muqaddimah dustur. If they do not refer to the text of their book but apply it straight to the nash, then the ijtihad will not violate what has been outlined in hizb books. In the field of worship, it becomes individual responsibility. HTI Malang city officials suggest that every member of HTI should ideally use the strongest arguments (metode tarjih) in ritual practices.

Penelitian ini mengkaji pandangan aktivis HTI Malang terhadap metode ijtihad HTI dalam bidang politik dan Ibadah. Dengan menggunakan metode kualitatif dan interview, penelitian menghasilkan kesimpulan bahwa metode ijtihad aktivis HTI dalam bidang politik diawali dengan fahmul waqi' dan fahmul nash serta metode yang dirumuskan HT (ijtihad manhaji). Kalau permasalahan lama, cukup mengambil rujukan (aplikatif) dalam kitab-kitab HT seperti sistem pemerintahan dalam Islam, dan muqaddimah dustur. Jika merekaTidak merujuk pada teks kitabnya tapi langsung ke nashnya, maka ijtihadnya tidak akan menyalahi apa yg sudah digariskan dalam buku-buku hizb. Sedangkan dalam bidang ibadah diserahkan kepada masing-masing individu. Petinggi HTI kota Malang dalam persoalan ritual ibadah menginginkan agar setiap anggota HTI idealnya memakai dalil terkuat (metode tarjih)
\end{abstract}

Kata Kunci: Ijtihad, Fahmul waqi', Fahmul nash,

Dalam sejarah bangsa telah berdiri berbagai kekuatan Islam dan organisasi sosial keagamaan di kalangan umat Islam. Setidaknya dapat disebutkan seperti Sarekat Islam (SI), Muhammadiyah, Persis, Al-Irsyad, NU, Jong Islamieten Bond (JIB), Masyumi, Nahdlatul Wathan, PII, ICMI, dan sebagainya. Dewasa ini yang paling banyak mewarnai perkembangan politik, sosial dan budaya adalah Muhammadiyah dan NU.

Demikian pula untuk urusan perkembangan Hukum Islam khususnya masalah Ijtihad. Membicarakan hukum Islam tentunya tidak lengkap jika tidak menyinggung yang namanya $i q h$. Kata fiqh, dalam AlQuran disebut dalam bentuk kata kerja ( $f$ ' $i l$ ) sebanyak 20 kali. Penggunaannya, fiqh berarti memahami (QS. Al-An'am: 65, Al-A'raf: 179, Al-Anfal: 65, AlTaubah: 81, 87, 127 dan Al-Munafiqun: 3). Secara harfiah, fiqh artinya faham. fiqh menekankan pada penalaran, meskipun secara epistimologis ia terikat pada wahyu. Sebagai produk pemikiran hukum, fiqh adalah hukum-hukum syara' yang bersifat praktis yang diperoleh dari dalil-dalil yang rinci. ${ }^{1}$

Seperti yang telah kita ketahui, fiqh merupakan produk zaman dari para mujtahidin yang telah berupaya mendialogkan antara prinsip-prinsip ajaran di satu pihak dan konteks sosial yang berkembang di pihak lain. ${ }^{2}$ Produk-produk zaman dari para mujtahidin tentunya tidak luput juga dengan nyawa atau spirit dari fiqh itu sendiri. Nyawa atau spirit dari fiqh adalah ushul fiqh yang dalam pandangan Syaikh Mustafa Abdurraziq disebut sebagai Filsafat yang tumbuh sendiri dan orisinil dalam Islam³ .

\footnotetext{
Totok Jumantoro, Kamus Ilmu Ushul Fiqh, (Jakarta: Amzah, 2005), 6368; Ahmad Rofiq, Pembaharuan Hukum Islam Di Indonesia, (Yogyakarta: Gama Media, 2001), 16-17; lihat juga Amir Syarifudin, Ushul Fiqh jilid 1, (Jakarta: logos, 2001).

2 Asep Saeful Muhtadi, Pribumisasi Islam: Ikhtiar Menggagas Fiqh Kontekstual, (Bandung: Pustaka Setia, 2005), 56.

Syaikh Mustafa Abdurraziq secara ilmiah telah menolak beberapa
} 
Ushul Fiqh sebagai Filsafat yang tumbuh sendiri dan orisinil dalam Islam juga menjelaskan tentang rahasia-rahasia, makna, hikmah, dalil serta nilai-nilai yang terkandung dalam Qur'an dan Sunnah. Rahasia-rahasia, makna serta dalil yang terkandung dalam Qur'an dan Sunnah tersebut dapat kita temukan dengan cara ijtihad baik secara individu maupun kolektif, sehingga kita dapat melaksanakan ketentuan-ketentuan Islam disertai dengan pengertian dan kesadaran yang tinggi. Dengan kesadaran hukum masyarakat ini akan tercapai ketaatan dan disiplin yang tinggi di dalam melaksanakan hukum.

Ijtihad dapat dilakukan oleh ulama secara individual bahkan secara kolektif dengan epistemologi yang mereka miliki. Ijtihad dari seorang ulama pada akhirnya akan menghasilkan sebuah fatwa. Fatwa sebagai legal opinion, tidak bersifat mengikat, tetapi hanya merupakan informasi hukum untuk kebutuhan sendiri. Pada masa lalu, legal opinion yang tidak mengikat itu dilakukan oleh individu. Kini, karena kelangkaan mufti yang berkualitas, pekerjaan ini diambil alih oleh lembaga yang beranggotakan banyak orang yang ahli dalam fiqh dan ushul fiqh. ${ }^{4}$ Keadaan demikian tak terkecuali untuk Indonesia.

Hingga awal abad dua puluh, perumusan fatwa hanya dilakukan oleh ulama secara perorangan. Namun pada kuartal kedua abad dua puluh, beberapa telah mulai dilakukan oleh ulama secara kolektif ${ }^{5}$ melalui sebuah lembaga yang dalam hal ini, demi merespon problem-problem dari masyarakat Indonesia yang majemuk, mayoritas 90 persen beragama Islam, beraliran sunni yang konon menganut mazhab Syafi'i. ${ }^{6}$ Ikhtiyar untuk merespon problem masyarakat telah dilakukan oleh ulama secara kolektif di beberapa lembaga fatwa di bawah naungan ormas-ormas Islam seperti: Majelis Tarjih Muhammadiyah, ${ }^{7}$ Bahtsul

analisis Orientalis dan sarjana Barat yang mengatakan bahwa Islam tidak mempunyai Filsafat. Filosof muslim hanya menyalin atau secara kasarnya, "plagiat" saja dari filsafat Yunani. Maka Syaikh Mustafa Abdurraziq telah mengemukakan teorinya yang tidak dapat dibantah bahwa Islam mempunyai Filsafat yang tumbuh dalam Islam sendiri yang orisinil bukan plagiat, yang terutama ialah ilmu Ushul Fiqh garapan dari Imam Muhammad Idris AsySyafi'ie. Baca: Hamka, Studi Islam, (Jakarta: Pustaka Panjimas, 1983), 2829.

4 Rifyal Ka'bah, Penegakan Syariat Islam di Indonesia (Jakarta: Khairul Bayan, 2004), 217; Maskun, "Problematika Aplikasi Produk Pemikiran Hukum Islam di Indonesia," Mimbar hukum No. 49, (Jakarta: al-hikmah, 2000), 41.

5 Maskun, Loc. cit.

6 M. Abdul Karim, Sejarah Pemikiran dan Peradaban Islam (Yogyakarta: Pustaka Book Publisher, 2007), 331.

7 Lihat: Fathurrahman Djamil, Metode Ijtihad Majlis Tarjih Muhammadiyah, (Jakarta: Logos, 1995)

8 Lihat Ahmad Zahro, Tradisi Intelektual NU (Yogyakarta: Lkis, 2004), 166174; Soelaiman Fadeli dan Mohamad Subhan, Antologi NU (Surabaya: Khalista, 2007), 35-36; Rumadi, Post-Tradisionalisme Islam: Wacana Intelektualisme dalam Komunitas NU (Cirebon: Fahmina Institute, 2008),
Masa'il NU, ${ }^{8}$ Dewan Hisbah Persatuan Islam, ${ }^{9}$ dan Dewan Syariah Pusat PK Sejahtera. ${ }^{10}$

Di luar lembaga fatwa tersebut ada beberapa ulama yang $f a q i h$ melakukan ijtihad secara individual baik berupa fatwa atau gagasan dalam bentuk tsaqofah Islam yang dituangkan dalam beberapa karya ilmiah. Ulama yang saya maksud diantaranya: A. Hassan (Persis), ${ }^{11}$ Abdul Qodir Hassan (Persis), ${ }^{12}$ Sulaiman Rasyid dengan bukunya yang best seller "Fiqih Islam". Hazairin dengan teori receptie exit, gagasan mazhab Indonesia dan gagasan hukum kewarisan bilateral, ${ }^{13}$ Hasbi Ash-Shiddiqie dengan gagasan fiqh Indonesia. ${ }^{14}$

Tokoh-tokoh lainnya yang tidak boleh dilupakan adalah M. Quraish Shihab sebagai pakar tafsir terkemuka Indonesia pada akhir dekade rezim Orde Baru, beliau adalah seorang penulis karya-karya keislaman yang sangat produktif, salah satu buah karyanya yang berisi ratusan produk ijtihadnya ialah 1001 soal keislaman yang patut anda ketahui. ${ }^{15}$ Masyfuk Zuhdi dengan bukunya Masail Fiqhiyah, yang membicarakan persoalan-persoalan kontemporer, yang ditulis sebagai buku teks mahasiswa. Di dalamnya lebih berorientasi fiqh dan solusi dengan penggunaan kaidah ushul dan fiqhiyah. Selanjutnya Ali Yafie dengan bukunya Menggagas Fikih Sosial, dan Sahal Mafudh ${ }^{16}$ yang menuangkan gagasannya dalam buku Nuansa Fiqih Sosial. Kehadiran dua buku fiqh sosial yang dirilis pada akhir dekade kekuasaan rezim Orde Baru ini menunjukkan betapa pentingnya upaya pengembangan Hukum Islam dengan semangat dan nuansa keindonesiaan dalam mengantisispasi perubahan dan perkembangan. ${ }^{17}$

82-89; Luthfi Hadi Aminudin, "Nalar Fiqh NU: Dari Tradisional, Modern hingga Liberal" dalam Tim PW. LT-NU Jawa Timur (ed), Sarung dan Demokrasi: Dari NU untuk Peradaban Keindonesiaan (Surabaya: Khalista; 2008), 31-43

9 Lihat: Uyun Kamiludin, Menyorot Ijtihad Persis (Bandung: Tafakur, 2006), 81-84; Dede Rosyada, Metode Kajian Hukum Dewan Hisbah Persis (Jakarta: PT. Logos wacana Ilmu, 1999), 184-190.

10 Dewan Syariah Pusat PK Sejahtera, Fatwa-Fatwa Dewan Syariah Partai Keadilan Sejahtera (Bandung: Harakatuna Publishing, 2006), x-xi.

11 Untuk mengetahui lebih dalam pokok-pokok pemikiran A. Hassan, lihat A. Hassan, Soal Jawab Masalah agama Vol. 1-2, (Bangil, 1996); A. Hassan, Kumpulan Risalah A. Hassan (Bangil: Pustaka Elbina, 2005).

12 Lihat: A. Qadir Hassan, Kata Berjawab: Solusi Untuk Berbagai Permasalahan Syariah, jld 1-2 (Surabaya: Pustaka Progresif, 2006).

13 Hazairin, Hukum Kewarisan Bilateral menurut Qur'an dan Hadith (Jakarta: Tintamas, 1982), 29.

14 Lihat Norouzzaman Shiddiqi, Fiqh Indonesia: Penggagas dan Gagasannya (Yogyakarta: Pustaka Pelajar, 1997).

15 Quraish Shihab, 1001 Soal Keislaman yang Patut Anda Ketahui (Jakarta: Lentera Hati, 2008).

16 Mengenai produk istinbath hukum KH. Sahal, baca: Sahal Mafudh, Dialog dengan Kiai Sahal Mafudh: Solusi Problematika Umat (Surabaya: LTN NU Jawa Timur, 2003).

17 Ahmad Rofiq, op.,cit, 53. 
Setelah membicarakan kondisi obyektif perkembangan fiqh dari era A. Hassan hingga Sahal Mafudh, tanpa terasa waktu pun berlalu. Ditandai dengan terjadinya krisis ekonomi pada pertengahan tahun 1997 lalu, bangsa Indonesia mengalami gema tuntutan reformasi yang digerakkan oleh para mahasiswa menghentakkan atmosfir kehidupan nasional. Meskipun bermula dari krisis ekonomi, bola tuntutan reformasi itu bergulir deras ke bidang politik. Presiden Suharto pun dengan berat hati melepaskan jabatan presiden yang sudah digenggam selama 32 tahun. ${ }^{18}$

Pasca runtuhnya rezim Orde Baru, membuat bangsa Indonesia memasuki periode baru yang disebut era reformasi, sejak bergulirnya era reformasi tahun 1998, semua orang bisa berbicara tentang apa saja dengan bebas, termasuk mengemukakan ide-ide atau pendapat yang berkaitan dengan Islam; sesuatu yang di zaman Orde Baru sangat dilarang seperti formalisasi Syariat Islam, Piagam Jakarta, Perda bernuansa Islam, bahkan keinginan untuk mendirikan kembali Ormas dan Partai Politik berasaskan Islam.

Memasuki millenium ke-3 atau abad ke-21 ini, tiba-tiba muncul dan berkembang pesat gerakangerakan Islam di luar Muhammadiyah, Persis, NU maupun ICMI. Di antara gerakan-gerakan itu, terdapat gerakan Tarbiyah yang kemudian menjelma menjadi Partai Keadilan Sejahtera (PKS), Hizbut Tahrir Indonesia (HTI), Majelis Mujahidin Indonesia (MMI), Front Pembela Islam (FPI), Kesatuan Aksi Mahasiswa Muslim Indonesia (KAMMI), Laskar Jihad, dan Salafi.

Gerakan-gerakan ini muncul secara fenomenal dan kontroversial. Fenomenal karena mampu berkembang sangat cepat dan menarik banyak pihak. Mereka berhasil mendirikan cabang-cabang, dan mendapat pengikut serta simpatisan yang cukup pesat. Kontroversial, karena sebagian dari mereka ada yang melakukan kegiatan sweping terhadap diskotik, warung remang-remang dan remaja yang sedang berbuat asusila hingga penggrebekan terhadap penganut aliran sesat. Sehingga fenomena tersebut menimbulkan pro-kontra di masyarakat.

Pro-kontra itu bisa dipahami oleh karena di antara gerakan-gerakan ini ada yang menurut pengamat gerakan Islam cenderung bersikap militan dan radikal. ${ }^{19}$ Namun, di sisi lain, di antara gerakan-gerakan tersebut ada yang bersikap moderat, simpatik dan

18 Al-Chaidar, Reformasi Prematur: Jawaban Islam Terhadap Reformasi Total (Jakarta: Darul Falah, 1998), viii.

19 Lihat: Endang Turmudi dan Riza Sihbudi (ed), Islam dan Radikalisme di Indonesia (Jakarta: LIPI Press, 2005). memberikan layanan-layanan publik. Selain itu, prokontra disebabkan oleh faktor-faktor lain seperti persaingan politik ataupun kepentingan pribadi, dan boleh jadi dikarenakan sebagian besar kalangan masyarakat belum cukup mengenali siapa mereka sebenarnya.

Salah satu dari gerakan-gerakan di atas yang tentu saja fenomenal dan militan sebagaimana masyarakat ketahui adalah Hizbut Tahrir Indonesia (HTI). HTI merupakan sebuah Partai Politik dan Dakwah di jalur ekstra parlemen. Jika ditelusuri sejarahnya, HTI bukan barang baru. Ia masuk ke Indonesia pada 19821983. Walaupun sudah lebih dari 25 tahun eksis, akan tetapi selama ini masyarakat hanya mengenal gerakan HTI dari pengajian, media massa sekuler, isu-isu yang beredar baik di internet maupun pengajian ${ }^{20} \mathrm{Se}-$ lebihnya pokok-pokok pikiran mereka dapat dengan mudah kita ketahui melalui peredaran buletin dakwah al-Islam setiap hari jum'at. HTI memang fenomenal untuk urusan politik, tercatat sudah dua kali mereka menggelar konferensi Khilafah Islamiyah pada tahun 2000 dan terakhir pada tahun 2007 kemarin. ${ }^{21}$ Seluruh kegiatan yang dilakukan Hizb mayoritas bersifat politik (dakwah siyasi). Karena menurut mereka yang dimaksud politik adalah mengurus dan memelihara urusan-urusan masyarakat sesuai dengan hukumhukum Islam dan pemecahan-pemecahannya. Dalam kesehariannya aktivis HTI juga menonjol aktivitas politiknya sebagaimana lazim kita temui antara lain: mashiroh (pawai damai), diskusi panel di berbagai kampus, Tabligh Akbar, Manifesto HTI, kampanye penegakan syariat Islam dengan metode Khilafah, ${ }^{22}$ anti berkoalisi dengan kelompok sekuler, dan Golput ketika pemilu ${ }^{23}$.

Begitu pula untuk persoalan ritual ibadah, mereka juga militan. Sebagaimana yang sering kita temui: Sholat hari raya Idul Fitri dan Idul Adha berdasarkan metode Rukyatul global, ${ }^{24}$ pola pergaulan

20 Menurut beberapa anggota jama'ah tahlil di sebuah kampung, yang cenderung curiga terhadap gerakan HTI dan PKS, mereka menganggap bahwa HTI dan PKS adalah organisasi yang sama. Bahkan, dari percakapan mereka ada yang menstigma gerakan HTI dan PKS sebagai Islam garis keras, wahabi yang mengancam eksistensi ritual tahlilan.

21 Redaksi, "100 ribu Orang Akan Hadiri Konferensi Khilafah Internasional di Jakarta" www.syabab.com di akses pada 4 mei 2009 pk. 10.32 .

22 Lihat Hizbut Tahrir, Struktur negara Khilafah: Pemerintahan dan Administrasi (Jakarta: HTI Press, 2008); Abdul Kareem Newell, Akuntabilitas Negara Khilafah, ebook dalam Format Pdf, Di download dari http//rizkisaputro.wordpress.com. Tim redaksi, "Mengapa Harus Khilafah: Renungan 80 tahun tanpa Khilafah" buletin al-Islam Edisi 193 tahun 2004.

23 Sapto Waluyo, Kebangkitan Politik Dakwah (Bandung: Harakatuna Publishing, 2005), 58.

24 Hizbut Tahrir dalam menetapkan awal Ramadhan dan Syawal berdasarkan rukyat global yakni jika bulan terlihat disuatu negeri, maka negeri yang lain wajib mengikutinya. Lihat Tim redaksi, "Perbedaan awal-akhir Ramadhon: Sebuah Persoalan Politik," al-Islam Edisi 34 tahun 1421 H; M. Shiddiq al-Jawi, "Penentuan Awal Bulan Kamariyah: Perspektif Hizbut Tahrir Indonesia“, Makalah disampaikan dalam Seminar Nasional 
yang sangat menghindari ikhtilat, cara berpakaian aktivis perempuan HTI yang menggunakan stelan baju berukuran longgar dan lebar. namun di satu sisi ritual ibadah mereka tidak seragam. Ada yang pakai bacaan doa qunut ketika Sholat shubuh ada juga yang tidak, kemudian tidak semuanya terlihat berjenggot, berisbal atau pakai baju gamis seperti orang salafi. Kalau dicermati lebih lanjut, realitas ekspresi ritual ibadah mereka akan tampak tidak menunjukkan adanya keseragaman sebagaimana halnya aktivitas politik mereka yang cenderung seragam. Mengapa tampak tidak begitu kompak dan seragam sebagaimana halnya aktivitas politiknya? Padahal HTI dalam setiap aktivitasnya sehari-hari berkomitmen kepada hukum syara' (Quran, Sunnah, Ijma' sahabat dan Qiyas). Guna menjawab hal tersebut harus terlebih dahulu kita ketahui bagaimana metode ijtihad HTI dalam bidang politik dan bagaimana pula metode ijtihad HTI dalam bidang ibadah.

Berawal dari temuan-temuan barusan, Peneliti jadi ingin mengetahui bagaimana pandangan aktivis HTI tentang metode ijtihad mereka dalam bidang politik dan ibadah. Penelitian yang akan saya lakukan juga turut terbantu oleh legalnya aktivitas dakwah mereka di Indonesia. Dengan begitu, peneliti mudah melacak berbagai nasyrah, buku-buku, mengikuti seminar/halaqoh dan kumpulan pandangan aktivis HT yang tersebar di Internet yang berhubungan dengan penelitian ini. Oleh karena itu secara komprehensip akan dituangkan ke dalam sebuah karya ilmiah dengan judul "Pandangan Aktivis Hizbut Tahrir Indonesia (HTI) di Malang tentang metode ijtihad HTI dalam Bidang Politik dan Ibadah.”

\section{Metode Penelitian}

Penelitian ini adalah penelitian lapangan (field reseach) yakni penelitian dengan sumber data yang ada pada masyarakat sosial ataupun institusi tertentu. Sesuai dengan tempatnya, maka penelitian ini dilakukan pada aktivis HTI di Kota Malang. Dalam hal ini peneliti mencoba memahami pendapat atau pandangan aktivis HTI kota Malang tentang metode ijtihad HTI dalam bidang politik dan ibadah. Pandangan seseorang aktivis HTI hanya dapat diketahui dengan terjun kelapangan melalui wawancara langsung dengan mereka.

bertema "Penentuan Awal Bulan Kamariah di Indonesia Merajut Ukhuwah di Tengah Perbedaan", diselenggarakan oleh Majelis Tarjih dan Tajdid PP Muhammadiyah, Kamis-Ahad, 27-30 Nopember 2008, di Universitas Muhammadiyah Yogyakarta, Yogyakarta.
Tidak lupa juga karena penelitian ini terkait dengan metode ijtihad, maka digunakan pendekatan normatif, yakni dari sudut pandang ilmu Ushul fiqh ${ }^{25}$ Dengan mengaplikasikan teori-teori ijtihad/istinbath hukum. Dalam pengumpulan data digunakan metode wawancara dan dokumentasi. Sedangkan untuk mengolah dan menganalisa data digunakan metode editing, yakni data atau keterangan yang telah dikumpulkan dalam record book, daftar pertanyaan ataupun pada interview guide perlu dibaca sekali lagi dan diperbaiki. Jika di sana-sini masih terdapat hal-hal yang salah atau masih meragukan. ${ }^{26}$ Setelah itu peneliti melakukan pengklasifikasian (pengelompokan) terhadap seluruh data-data penelitian, baik data yang diperoleh dari hasil observasi maupun data hasil wawancara (interview) yang berkaitan dengan tema penelitian agar lebih mudah dalam melakukan pembacaan dan penelaahan data sesuai dengan kebutuhan yang diperlukan. Hal ini dilakukan karena para informan penelitian tentunya sangat beragam (berbeda-beda) dalam memberikan informasi. Oleh karenanya kemudian peneliti mengumpulkan data-data yang telah diperoleh tersebut dan selanjutnya memilih mana data yang akan dipakai sesuai dengan kebutuhan. Langkah ketiga, peneliti melakukan verifikasi (pengecekan ulang) terhadap data-data yang telah diperoleh dan diklasifikasikan berdasarkan masalah yang telah dirumuskan. Hal ini bertujuan agar akurasi data yang telah terkumpul itu dapat diterima dan diakui kebenarannya oleh segenap pembaca. Dalam hal ini, peneliti menemui kembali pihak-pihak (informan-informan) yang telah diwawancarai pada waktu pertama kalinya, kemudian kepada mereka peneliti memberikan hasil wawancara untuk diperiksa dan ditanggapi, apakah data-data tersebut sudah sesuai dengan apa yang telah diinformasikan oleh mereka atau tidak. Tahapan selanjutnya adalah analisis sebagai tahap yang paling penting karena disinilah letak signifikansi penelitian ini. ${ }^{27}$

Metode analisis yang dipakai penulis adalah deskriptif kualitatif. Deskriptif merupakan penelitian non hipotesis sehingga dalam langkah penelitiannya tidak perlu dirumuskan hipotesis, sedangkan kualitatif adalah data yang digambarkan dengan kata-kata atau kalimat yang dipisah-pisahkan menurut kategori untuk memperoleh kesimpulan. ${ }^{28}$ Sehingga pada akhirnya dapat diperoleh gambaran yang jelas mengenai pan-

\footnotetext{
25 Cik Hasan Bisri, Pilar-Pilar Penelitian Hukum Islam dan Pranata Sosial, (Jakarta: Rajawali Press, 2004), 304-305

26 Moh. Nazir, Op, Cit., 346.

27 Suharsimi Arikunto, Op, Cit., 209-210.

28 Ibid. 204
} 
dangan aktivis HTI kota Malang mengenai metode ijtihad Hizbut Tahrir Indonesia dalam bidang politik dan ibadah. Langkah terakhir adalah concluding yaitu pengambilan kesimpulan dari data-data yang telah diolah untuk mendapatkan suatu jawaban, dimana peneliti sudah menemukan jawaban-jawaban dari hasil penelitian yang dilakukan.

\section{Hasil dan pembahasan}

Asal-usul gerakan HTI di Malang, awalnya dibawa oleh Ust Sya'roni pada tahun 1993 sebagai satusatunya anggota resmi. Pada waktu itu interaksi dakwah dibatasi pada segmen kampus, karena kampus adalah segmen dakwah yang paling cepat perkembangannya dan secara keintelektualannya cukup tinggi. Beliau menemukan ada orang-orang yang beberapa idenya itu sama, maka dapat disimpulkan, ternyata HTI sudah masuk ke Malang tapi belum secara kelembagaan alias masih secara (kelompok pemikiran), karena belum menemukan anggota resmi selain dirinya sendiri. ${ }^{29}$ Di luar apa yang telah dikatakan Sya'roni, ternyata menurut Syamsul Arifin, pada tahun 1990 di BDM al-Hikmah pernah mengadakan Daurah Dirasah Islamiyah (DDI), dengan menghadirkan pemateri top seperti: Muhammad al-Khathath (sekarang jadi Sekjen FUI dan Ketua Hizbut Dakwah Islam), Ismail Yustanto (sekarang Jubir HTI), Fathul Hidayat (sekarang aktivis Partai Bulan Bintang) dan Adian Husaini (sekarang Ketua Majelis Tabligh Muhammadiyah dan Ketua DDII). Acara DDI ternyata tidak hanya diikuti oleh mantan pengurus BDM al-Hikmah, tetapi juga diikuti oleh Sya'roni sebagai utusan LDK Universitas Negeri Jember. Dapat dipastikan persemaian ide-ide HT berawal DDI. ${ }^{30}$

Setelah DDI, beberapa tahun kemudian basisbasis HT di Malang mulai berkembang di dua kampus yaitu Universitas Brawijaya dan IKIP Malang. Karena rezin pada masa itu, lumayan represif, maka cara aktivis senior HT merekrut anggota baru dilakukan pembinaan dari rumah ke rumah, di masjid kampus khususnya ba'da sholat jamaah dengan melakukan halaqoh 'am. Dalam pengertian aktivis HT halaqoh 'am merupakan kegiatan yang dilakukan oleh aktivis HT untuk memperkenalkan Hizbut Tahir kepada orang-orang yang belum mengenal HT (awam). ${ }^{31}$ Di HT berlaku aturan mengikat setiap anggota resmi

\footnotetext{
29 Sya'roni, wawancara, (Malang, 25 Mei 2009)

30 Syamsul Arifin, Ideologi dan Praksis Gerakan Kaum Fundamentalis: Pengalaman Hizbut Tahrir Indonesia, (Malang: UMM Press, 2005), 124.

31 Ibid. 156. cara lainnya ide-ide HT disusupkan ke Pesantren, Sekolahsekolah Muhammadiyah dan LDK.
}

agar mengadopsi dan menyebarluaskan ide-ide HT ke publik. ${ }^{32}$

Pada periode 1990-an hingga awal th 2000, aktivitas dakwah HT di kawasan Malang hanya sebatas fase marhalah tatsqif (pembinaan dan pengkaderan). Jadi mereka banyak melakukan pembinaanpembinaan intensif, baik dari internal maupun ke masyarakat. Jadi istilahnya itu dalam bahasa mereka "membesarkan tubuh dulu" dan untuk yang seperti itu tidak perlu kegiatan yang sifatnya besar dan mencolok di muka umum. ${ }^{33}$

Baru sejak tahun 2002, menurut Umi sumbulah Gerakan dakwah HT di Malang terformat dengan kegiatan dan program yang jelas. Dengan melakukan publikasi kepada masyarakat, diharapkan ada pemahaman yang benar, sehingga tidak dikatakan sebagai "gerakan bawah tanah" yang mudah disusupi oleh pihak lain. Perbedaan HT tahun 1995-an dengan era reformasi, bahwa era reformasi memberikan banyak kesempatan kepada HT untuk mempublikasikan ideidenya secara terbuka. di samping melalui tulisantulisan, proses pembelajaran politik di masyarakat juga dilakukan dengan demo. ${ }^{34}$

Saat ini HT di Malang diketuai oleh Ust Abdul Malik. Beliau adalah seorang dosen di Perguruan Tinggi ternama di Malang. Beliau ternyata sudah lama jadi pimpinan sejak tahun 2002 hingga sekarang belum ada yang menggantikan. ${ }^{35}$ Di Struktur DPD II HTI Malang, untuk jabatan Sekretaris dipegang oleh Ust Yusuf dan Humasnya adalah Ust Sya'roni.

Menurut Abdul Malik, Lajnah-lajnah yang ada di setiap DPD bersifat fungsional, masing-masing ada di setiap kota besar. Sedangkan pada kota-kota kecil tidak ada lajnah. Berikut ini susunan pengurus HTI kota Malang (Tabel I): ${ }^{36}$

\section{Pandangan Aktivis Hizbut Tahrir Indonesia (HTI) di Malang tentang metode ijtihad HTI dalam Bidang Politik dan Ibadah}

Seluruh kegiatan yang dilakukan HTI mayoritas bersifat politik (dakwah siyasi). Maksudnya adalah bahwa Hizb memperhatikan urusan-urusan masyarakat sesuai dengan hukum-hukum serta pemecahannya secara syari'i. Karena menurut mereka yang dimaksud politik adalah mengurus dan memelihara

\footnotetext{
32 Sya'roni, wawancara, (Malang, 25 Mei 2009)

33 Abdul Malik, wawancara, (Malang 20 Mei 2009)

34 Umi Sumbulah, "Gerakan fundamentalisme Islam di Malang studi atas Hizbut Tahrir, Majelis Mujahidin, dan Arimatea," Istiqro', Vo 16 No. 1 (Jakarta: Departemen Agama, 2007), 20.

35 Abdul Malik, wawancara, (Malang 20 Mei 2009)

36 Ibid.
} 
Tabel I

Susunan Pengurus HTI Kota Malang

\begin{tabular}{|clll|}
\hline No. & \multicolumn{1}{c}{ Lajnah-Lajnah } & \multicolumn{1}{c|}{ Ketua } & \multicolumn{1}{c|}{ Tugas dan fungsi } \\
\hline 1 & Tsaqofah & Abdurrohim & $\begin{array}{l}\text { Menerbitkan/menyebarkan luaskan nasyrah, Fiqh } \\
\text { praktis, Counter pemikiran liberal }\end{array}$ \\
\hline 2 & Siyasah & Suwardi & Mengurusi bidang politik \\
\hline 3 & Maslahiyah & Abu dzikri & $\begin{array}{l}\text { Merespon isu-isu yang berkembang di } \\
\text { masyarakat }\end{array}$ \\
\hline 4 & Fa'liyah & Sya'roni & Humas/Kontak dakwah \\
\hline
\end{tabular}

urusan-urusan masyarakat sesuai dengan hukumhukum Islam dan pemecahan-pemecahannya.

Para informan dalam wawancara dengan peneliti mayoritas keterangan mereka seragam dalam menjelaskan definisi politik menurut Hizbut Tahrir, berikut ini keterangan mereka:

Ustadz Abdul Malik, berpendapat, "HT mendefinisikan Politik sebagai riayatul syu unil ummah (mengurusi umat), bagaimana sesungguhnya mengurusi kepentingan umat. Tidak identik politik itu dengan yang namanya politik praktis, bahkan ketika politik praktis itu menghilangkan esensi dari mengurusi kepentingan umat, ini yang kemudian dijauhi oleh HT. Apapun labelnya ketika urusan umat tidak menjadi prioritas utama, maka itu menurut HT bukan masalah poltik, meskipun orang itu mengklaim sebagai aktivitas atau partai politik. "37

Ustadz M. Rozikin, juga berpendapat,

"Bahwasanya siyasah itu bermakna Riayatul syu unil ummah. Mengurusi kepentingan umat. Politik itu pelaksanaannyaadalahdilaksanakanolehdaulah dan juga umat. Cuma peranannya beda. Aktivitas riayah/mengurus dilakukan secara real (nyata) oleh daulah, sedangkan peran umat adalah mengontrol." 38

Setelah mengetahui konsepsi politik HTI dari informan, peneliti langsung menanyakan bagaimana metode ijtihad HTI dalam hal politik?

Ustadz Abdul Malik, mengatakan,

"Politik dalam arti mengurusi ummat, yang kita kedepankan adalah 2 hal, tafkirul hukmi dan tafkirul siyasi. Tafkirul hukmi ini kita berfikir status hukumnya apa, halal atau haram. Misalkan tentang pemilihan presiden, kita berbicara boleh-tidaknya seseorang mencalonkan diri. Ada lagi yg namanya tafkirul siyasi, berfikikir secara politis, artinya pertanyaannya bukan masalah halalharam, tapi pertanyaannya mengapa terjadi, dan kemudian kira-kira solusi kedepannya seperti apa.

Kalau seperti nasyrah hukum pemilu, kita lihat 2 hal, tafkirul hukmi dan siyasi. Bisa juga pembuat nasyrah itu mengimplementasikan kaedah-kaedah yang tercecer di dalam buku-buku hizb itu menjadi suatu pembahasan yang terfokus pada masalah tertentu. Maka ijtihadnya para syabab dalam hal politik pun tidak akan menyalahi metode yg sudah digariskan dalam buku-buku hizb. ${ }^{39}$

Ustadz Alwan, berpendapat,

"Bagaimana langkah-langkah hizb dalam merespon persoalan hukum terutama yang berkaitan dengan politik? Hizb merangkum dalam konsepsi yang disebut dengan fikroh. Di dalam fikroh ada tiga point pokok, yang pertama adalah berkaitan dengan persoalan fakta. Kedua, hukum. Sedangkan ketiga, mengaitkan antara fakta dan hukum. Analisa sebuah fakta tidak didasarkan kepada sebuah asumsi tetapi kepada realitas. Fakta didalami dan dihukumi 
dengan hukum syara'itulah yang disebut istinbath.

Mengenai persoalan ijtihad politik, Hizb banyak mengambil rujukan (aplikatif) dalam buku Sistem Pemerintahan dalam islam, yang kedua, Muqaddimah dustur. Di muqaddimah dustur itu yang paling banyak dijadikan rujukan.

Apabila dalam hal ijtihad politik tersebut mengharuskan seluruh syabab mengadopsinya. Maka di institusi hizb pusat ada sebuah lajnah yang membahas persoalan fiqhiyah. Yaitu yang disebut dengan lajnah tsaqofiyah." 40

Ustadz Rozikin, menguraikan dengan panjang lebar bahwa,

"Pertama, saya rasa lebih dekat ke ijtihad manhaji, artinya dalam berijtihad tidak merujuk pada teks kitab HT, tetapi metode yang dirumuskan HT. Kedua, ketika ada persoalan-persoalan yang muncul di masyarakat, HT kan punya kitab-kitab yang menjelaskan tentang hukum syara' disertai dalilnya, HT ketika merespon sesuatu tidak merujuk ke teks kitab-kitab HT. Seperti di Bahtsul masail NU kan merujuknya ke teks kitab toh.... misalkan ada persoalan ini, dalam syarah al-bujairimi begini, dalam almuhadzab ada ibaroh yang bunyinya begini. Hizbut Tahrir tidak seperti itu, nggak teks di copy paste. Dalil yang dipakai untuk menjelaskan suatu hukum itulah yang dipakai. coba dilihat di nasyrah hukum pemilu legislatifini, pake nash kan. misalkan hukum wakalah, itu mengutipnya itu bukan mengutip "Dalam kitab Hizbut Tahrir yang...." tapi langsung ke nashnya. Harapannya dengan model kayak gini itu kaum muslimin jadi terbangkitkan lagi untuk berijtihad. jadi mengenai nash itu langsung dari sumbernya.

Nasyrah biasanya dikeluarkan oleh HTI pusat, ditulis oleh salah seorang syabab yang dipandang keilmuannya. Kemudian dikoreksi langsung oleh pim-

40 Alwan, wawancara (Malang, 16 Desember 2009) pinan HT pusat di timur-tengah. Setelah dikoreksi baru disebarkan. Dalam politik ijtihadnya dilakukan oleh perorangan. Tidak ada ijtihad kelompok. Kita menolak ijtihad kelompok. "'41

Ustadz Sya'roni juga berpendapat sama, "Kalau terkait ijtihad. Berarti fahmul waqi' dan fahmul nash. Memahami faktanya dulu, jadi hukum ini sangat tergantung daripada kebenaran kita melihat fakta. Ketika melihat fakta ini salah, maka bisa jadi hukum yang dihasilkan salah. Yang kedua tergantung memahami nash: Qur'an, Sunnah, ijma' sahabat maupun qiyas. Memahami nash ini, memang nashnya ini sesuai dengan fakta ini apa enggak, maksudnya nashnya untuk fakta itu. Misalnya memahami fakta sudah benar, tapi memahami nash salah, hasilnya juga salah. Jadi dibutuhkan dua hal ini benar.

Ijtihad itu bagian dari proses berfikir, pemikiranitukandefinisinya, memberikan hukum terhadap suatu realita atau membuat kesimpulan terhadap sebuah realitas. Kemudian kita itu menggunakan tahqiqul mannat, hukumnya itu sudah ada hanya mannatnya (obyek yang dikenai hukum) pas atau enggak

Hasil ijtihad dalam hal politik biasanya kami merujuk ke kitab mu'tabaroh itu, Struktur daulah khilafah dan sebagainya, kalau prees realese (nasyrah) untuk menangggapi persoalan politik yang lebih real, jawabannya sudah ada dalam kitab-kitab HT. Jadi tahqiqul mannat saja." ${ }_{42}$

\section{Metode ijtihad dalam bidang Ibadah}

Setelah mengetahui pandangan aktivis HTI kota Malang tentang metode ijtihad dalam hal politik, peneliti juga menanyakan kepada mereka tentang bagaimana metode ijtihad mereka dalam hal ibadah. Berikut ini penjelasannya:

Ustadz Abdul Malik, Mengatakan

"Ibadah itu adalah sesuatu yang tauqify,

41 M. Rozikin, wawancra (Malang, 16 Desember 2009)

42 Sya'roni, wawancara (Malang, 29 Mei 2009) 
diambil apa adanya. Sehingga kalau kita berbicara ibadah cukup hanya mendasarkan pada nash saja. Selama ada dalil dan apa yang ditunjukkan oleh dalil itu yg kemudian kita lakukan. Tapi jangan dikira kita berbicara pada halal atau haramnya saja. Ya harus dijelaskan apa hikmah dibalik itu.

HT Tidak banyak mengadopsi hal-hal yang berkaitan dengan masalah ibadah. Sedikit sekali atau bahkan nyaris tidak ada... kecuali ibadah-ibadah itu yang memang kalau tidak diadopsi bisa memunculkan keresahan, maka HT perlu mengasih contoh seperti rukyatul global, kalau itu dikaitkan dengan ibadah, kan masuk masalah ibadah, karena sebagai sebab pelaksanaan sebuah ibadah. Malah seperti syabab pakai qunut apa tidak, soal lamastumun nisa, itu tidak diadopsi oleh HT. yang penting selama ada dalilnya.

Metode ijtihad dalam hal ibadah dikembalikan kepada masing-masing syabab. Kalau dia mampu melakukan ijtihad ya silahkan berijtihad, kalau tidak mampu cukup juga muqalid mutabi' atau am. Tetapi idealnya ketika ia jadi muqallid hendaknya melakukan apa yg disebut dengan metode tarjih. Istilah lainnya Quwwatu dalil. Tarjih itu berarti mencari mana dalil mana yang lebih kuat, ada parameternya. Kalau dalilnya sama-sama kuat, ini boleh seseorang itu mengambil dari kapasitas kemampuan ilmu seorang ulama yang berijtihad itu, seperti alimnya"43

Ustadz Sya'roni, dalam persoalan metode ijtihad di bidang ibadah berpandangan

"Dalam fiqih ibadah kita berbeda dengan $N U$, tidak membatasi kepada 4 imam mazhab. Kita juga tetep menggunakan kitab-kitab klasik dan kontemporer untuk perkara yang sangat luas.

Misalnya kalau ambil 6 sampel fatwa ust Shiddiq al- jawi di tabloid Media ummat, metode baku ijtihad dalam hal

43 Abdul malik, wawancara (Malang, 9 Desember 2009) ibadah tidak ada, cuma perpaduan nash-nash Qur'an, kaidah-kaidah fiqh, tarjih. Kalau masalah lama yaa tidak harus berijtihad sendiri, mempelajari saja kitab-kitab klasik, argumentasinya seperti apa, tinggal ditarjih.

Secara pribadi saya dalam ritual ibadah terikat dengan mazhab Syafi'i, cuma aktivis HTIyang lain darimuhammadiyah amaliyahnya lebih dekat pada kebiasaan Muhammadiyah. Dalam persolan ibadah, kita obsesinya dalam HT ingin seseorang minimal pada level muqallid muttabi" 44

Ustadz Alwan, berpendapat bahwa

"Hizb sama sekali tidak mentabani persoalan ibadah karena ibadah merupakan persoalan nafsiyah, individual. Cuma kerangka pemahaman hizb untuk mengambil sebuah pendapat, yang dikatakan sebagai pendapat yang islami tetap berorientasi kepada quwwatu dalil. Quwwatu dalil seperti metode tarjih. Kalau dibutuhkan tarjih ya tarjih. Jadi mana yang dianggap dalilnya lebih kuat jadi itu yang harus diambil. Secara kerangka itu diberikan hizb kepada para anggotanya. Sehingga dengan demikian para anggota hizb dipersilahkan memilih mana yang dianggap oleh mereka itu sebagai dalil yang paling kuat. Macammacam diantara mereka itu akan melaksanakan sesuai dengan apa yang mereka ambil, tapi bukan sesuatu yang ditabani, jadi kerangkanya saja." ${ }^{45}$

Ustadz M. Rozikin berpendapat

"Dalam masalah ibadah diserahkan kepada masing-masing syabab. Intinya qur'an dan as-sunnah, ijma' sahabat dan qiyas syar'i. Nash dipahami apa adanya dengan memperhatikan nash yang ber-illat dan yang tidak ber-illat. Yang jelas tidak memakai qiyas dalam ibadah mahdah, karena yang dipahami oleh Hizb, semua nash-nash yang terkait dengan ibadah mahdah tidak ber-illat. Senantiasa juga kami berpegang pada 
kaedah "Dimana ada hukum syara' disana pasti ada mashlahat."

Apabila seorang syabab itu belum mampu berijtihad ya Bermazhab dalam pandangan hizb itu mubah."

\section{Pandangan Aktivis HTI Kota Malang Tentang Metode Ijtihad HTI Dalam Bidang Politik}

Dalam metode ijtihad politik, aktivis HTI terlebih dahulu mengetahui fakta (realitas) atas persoalan yang akan digali hukumnya, kemudian mengetahui nashnash syara' yang berkaitan dengan masalah tersebut dan terakhir mengerahkan segenap kemampuan dalam menggali hukum syara tentang suatu masalah dari nash-nash yang berkaitan dengannya. Ini merupakan langkah baku dalam buku-buku pegangan resmi Hizb ketika akan berijtihad. Jika ditelusuri lebih dalam, langkah baku ini merupakan rumusan yang dibuat pendiri Hizbut tahrir yaitu Taqiyudin an-Nabhani. Dalam buku Hakekat Berfikir, dijelaskan:

"Berfikir tentang hukum meskipun mem-
butuhkan pengetahuan bahasa arab dan
pemikiran-pemikiran Islam, tetapi sebelum
dan sesudahnya, juga membutuhkan pe-
mahaman tentang fakta. Kemudian mem-
butuhkan pengetahuan hukum syara', dan
selanjutya menerapkan hukum syara' ter-
sebut pada fakta" 46

46 Taqiyuddin an-Nabhani, Hakekat berfikir, (Bogor: Pustaka Thariqul Izzah, 2003), 169.
Langkah pertama dan kedua sudah sesuai prosedur, namun dalam langkah selanjutnya, mereka tidak maksimal dalam berijtihad langsung pada hukum syara'. Maksudnya, meskipun HTI mengakui alQur'an dan Sunnah merupakan sumber utama hukum Islam, namun dalam prakteknya, ijtihad dalam bidang politik ini tidak lantas dipahami sebagai "mengambil hukum secara langsung dari kedua sumber primer di atas, tetapi penggalian hukum dengan men-tathbiqkan (menerapkan) nash al-fuqaha' - terutama di kitab-kitab pegangan HT (mutabanah) - secara dinamis, dalam konteks permasalahan hukumnya."

Dapat peneliti simpulkan bahwa dalam ijtihad di bidang politik, aktivis HTI hanya melakukan sebatas metode ijtihad tathbiqi yaitu: Kegiatan ijtihad yang bukan untuk menemukan dan menghasilkan hukum, tetapi menerapkan temuan imam mujtahid terdahulu kepada kejadian yang muncul kemudian. ${ }^{47}$ Berarti kalau begitu konsep metode ijtihad mereka hanya sebuah wacana belaka? tidak digunakan secara maksimal, karena jawabannya sudah tersedia di kitabkitab karya ulama HT.

Sekarang kita bandingkan dengan NU yang sama-sama memiliki kitab-kitab pegangan/rujukan dalam berijtihad. NU dalam Bahtsul Masa'il kalau kita perhatikan keseluruhan hasil produk hukumnya khususnya mengenai masalah politik, kebanyakan mereka langsung merujuk bunyi teks kitab (kitab

47 Totok Jumantoro, op.cit., h. 116-119

Tabel II

Kesimpulan Metode Ijtihad HTI dalam Bidang Politik

\begin{tabular}{|c|c|c|c|}
\hline No. & Nama informan & Pandangan dalam wawancara & Metode ijtihad \\
\hline 1 & Abdul Malik & $\begin{array}{l}\text { Tafkirul hukmi dan tafkirul siyasi. mengimplementasikan } \\
\text { kaedah-kaedah yang tercecer di dalam buku-buku hizb itu } \\
\text { menjadi suatu pembahasan yang terfokus pada masalah. } \\
\text { Sehingga ijtihadnya tidak akan menyalahi apa yg sudah } \\
\text { digariskan dalam buku-buku hizb. }\end{array}$ & Ijtihad manhaji \\
\hline 2 & Alwan & $\begin{array}{l}\text { Mengambil rujukan (aplikatif) dalam buku Sistem } \\
\text { pemerintahan dalam islam, dan Muqaddimah dustur. }\end{array}$ & Ijithad tathbiqi \\
\hline 3 & Sya'roni & $\begin{array}{l}\text { fahmul waqi' dan fahmul nash. Kalau permasalahan lama, } \\
\text { cukup merujuk pada kitab-kitab HT dan Tahqiqul al- } \\
\text { mannath }\end{array}$ & $\begin{array}{l}\text { Ijtihad tahtbiqi } \\
\text { dan Tahqiqul al- } \\
\text { mannath }\end{array}$ \\
\hline 4 & M. Rozikin & $\begin{array}{l}\text { Pertama, dalam berijtihad memakai metode yang } \\
\text { dirumuskan HT. Kedua, tidak merujuk pada teksnya HT, } \\
\text { tapi langsung ke nashnya. }\end{array}$ & $\begin{array}{l}\text { Ijtihad manhaji dan } \\
\text { ijtihad tathbiqi }\end{array}$ \\
\hline
\end{tabular}


mu'tabarah).$^{48}$ Menurut Ahmad zahroh cara yamg dilakukan oleh NU ini disebut metode qauly. ${ }^{49}$

Sedangkan metode ijtihad aktivis HTI seperti yang dikatakan oleh M .Rozikin dalam wawancara, Pertama berijtihad memakai metode yang dirumuskan HT. Kedua, merujuk bukan pada teks/qoul kitab tapi cuma diambil dalil nashnya saja. Tapi perlu diketahui bahwa dalam urusan ijtihad politik HTI tidak sekedar bicara halal-haramnya saja namun memberikan sikap dan solusi atas problem tersebut, walaupun sangat normatif. Mengapa peneliti katakan normatif? Karena bisa kita tebak ujung-ujungnya solusi politik yang mereka tawarkan berkutat pada "ganti sistem dengan Khilafah."

Kemudian jika dibandingkan dengan metode ijtihad Persis yang di satu sisi punya komitmen slogan kembali kepada Qur'an dan Sunnah, Persis misalnya dalam fatwa tentang "Hukum Perempuan jadi Presiden/Kepala Negara" sebenarnya juga ada kemiripan dengan metode yang dilakukan aktivis HTI. Pertama, mengetahui fakta hukumnya. Kedua, baru mencari dalil-dalil yang terkait dengan problem yang akan dihukumi. Bedanya, para ulama Persis yang tergabung dalam Dewan hisbah, menggali dalil-dalilnya langsung dari Qur'an dan Sunnah (ijtihad bayani). Setelah itu mereka memutuskan hukumnya berdasar-

48 Dibandingkan dengan HTI, Persis maupun PKS. Bahtsul Masa'il NU jauh lebih produktif merilis fatwa yang berkaitan dengan masalah politik. Dari Awal muktamar pada th 1926 sampai th 2004 kemarin, tercatat sudah ada 14 fatwa yang berkaitan dengan soal politik.

49 Ahmad Zahroh, op. cit, 269 kan dalil yang telah ditemukan..$^{50}$

Bagaimana jika Metode ijtihad Hizbut Tahrir dalam bidang politik dibandingkan dengan metodenya ijtihadnya PKS?. Peneliti melihat ijtihad yang dilakukan saudara kembar HTI ini merupakan perpaduan antara ijtihad bayani, qiyasi dan ijtihad qouly (merujuk pada keterangan/teks kitab). Keunggulannya PKS dibanding dengan HTI, adalah kitab-kitab yang dipakai sebagai rujukan tidak terbatas pada kitabkitab klasik, kitab qawaid fiqhiyah dan kitab lintas mazhab saja, namun mereka memanfaatkan kitabkitab fiqih modern seperti Fiqhus Sunnah; Sayyid Sabiq, fiqih Islam dan dalil-dalilnya; Dr. Wahbah az-Zuhaily, Abdul Karim Zaidan, Mausu'ah Fiqih (Kuwait). ${ }^{51}$ Sedangkan HTI terikat dengan ide bahkan dalil-dalil di dalam kitab-kitab pegangannya sendiri, boleh dikatakan aktivis HTI untuk sementara waktu belum mampu melakukan metode ijtihad Insya'i yakni Pengambilan konklusi hukum baru dari suatu persoalan, yang persoalan itu belum pernah dikemukakan oleh ulama-ulama terdahulu, baik itu persoalan lama atau baru. Apakah mungkin dikarenakan sedemikian besarnya pengaruh pemikiran Taqiyudin an-Nabhani dalam hal politik?

Terakhir, peneliti menemukan satu kelebihan HTI dalam metode ijtihad politik, yakni apabila ijtihad tersebut dilakukan oleh institusi HTI pusat, apapun hasil dari ijtihad politik tersebut, suka atau tidak suka hasil keputusan hukum dalam bentuk nasyrah tersebut

50 Lihat Uyun kamiluddin, op, cit. 242-243

51 Lihat Ittijah Fiqh Dewan Syariah PKS

\section{Tabel III}

\begin{tabular}{|c|c|c|c|}
\hline No. & Nama informan & $\begin{array}{l}\text { Kultur keagamaan } \\
\text { Sebelum masuk HTI }\end{array}$ & $\begin{array}{l}\text { Pandangan tentang metode ijtihad dalam hal } \\
\text { ibadah }\end{array}$ \\
\hline 1 & Abdul Malik & Muhammadiyah & $\begin{array}{l}\text { Dikembalikan kepada masing-masing individu. } \\
\text { Idealnya Metode tarjih }\end{array}$ \\
\hline 2 & M Alwan & Persis & Quwwatu dalil/metode Tarjih \\
\hline 3 & Sya'roni & Nahdlatul ulama & $\begin{array}{l}\text { Untuk perkara yang luas, tidak membatasi kepada } \\
\text { kitab } 4 \text { mazhab, kitab-kitab kontemporer juga dipakai. } \\
\text { Permasalahan lama cukup mempelajari kitab-kitab } \\
\text { klasik dan di tarjih. Secara pribadi lebih dekat dengan } \\
\text { Mazhab syafi'i. Idealnya muqallid mutabi' }\end{array}$ \\
\hline 4 & M. Rozikin & NU-Tasawuf & $\begin{array}{l}\text { Tergantung individu masing-masing. Nash dipahami } \\
\text { apa adanya dengan memperhatikan nash yang ber-illat } \\
\text { dan yang tidak ber-illat. Tidak memakai qiyas dalam } \\
\text { ibadah mahdoh, berpegang pada kaedah "Di mana ada } \\
\text { hukum syara' maka disitu ada maslahat." Bermazhab } \\
\text { itu mubah }\end{array}$ \\
\hline
\end{tabular}


mengikat bagi setiap anggotanya dan wajib dipatuhi. ${ }^{52}$ Maka tidak mengherankan apabila aktivitas politik HTI sangat solid dan seragam. Hal yang sama juga peneliti lihat pada PKS. Berikut ini kesimpulan dari metode ijtihad HTI dalam bidang politik (Tabel II):

\section{Pandangan Aktivis HTI Kota Malang Tentang Metode Ijtihad HTI Dalam Bidang Ibadah}

Berbicara mengenai metode ijtihad HTI dalam bidang ibadah, ada beberapa catatan yang ingin peneliti uraikan: Pertama, dalam metode ijtihad di bidang ibadah, HTI secara institusi tidak ikut melakukan intervensi kepada jamaahnya. Bahkan hampir tidak ada yang arahan bagaimana metode baku dalam berijtihad di bidang ibadah. Hizbut Tahrir juga sama sekali tidak pernah membuat semacam kitab fiqh ibadah. Kedua, dapat kita lihat bagaimana jawaban/pandangan keempat informan tentang bagaimana metode ijtihad HTI dalam hal ibadah, tidak seragam. Sepertinya sangat dipengaruhi kultur keagamaan mereka sebelum masuk HTI. Kita harus tahu bahwa Aktivis HTI dulunya ada yang berlatar belakang kultur Nahdiyin, Muhammadiyah, Persis dan Ormas keagamaan lainnya (Tabel III) :

Dalam perkara yang sangat luas, para aktivis HTI menggunakan kitab-kitab dari berbagai mazhab untuk selanjutnya dicari mana dalil terkuatnya (tarjih). Cuma HTI tidak seperti NU yang tidak akan menggunakan kitab-kitab karya Ibnu Taymiyah, Yusuf Qardhawi, Wahbah zuhaily, Nashirudin al-banni, dan Syaikh bin Baz.

Mengenai metode tarjihnya, peneliti tidak bisa membandingkan dengan metode tarjih milik Muhammadiyah. Karena para informan kurang detail dalam menjabarkan proses metode tarjihnya. ${ }^{53}$ Walaupun tidak dijelaskan metode tarjihnya secara lengkap, tapi petinggi HTI kota Malang dalam persoalan ibadah menginginkan agar setiap anggotanya idealnya memakai dalil terkuat (metode tarjih). Apabila tidak bisa mentarjih sendiri, bermazhab atau bahasa lainnya taklid pun tidak dilarang. Asal kepada mujtahid yang dipercayai kadar keilmuwannya..$^{54}$

Persoalan pembolehan bermazhab dan taklid dalam urusan ritual ibadah di kalangan aktivis HTI sangatlah unik untuk dibahas lebih lanjut, mengapa? Karena HTI sebagai gerakan fundamentalis-intelektual mengambil sikap berbeda dengan gerakan fun-

\footnotetext{
52 Lihat wawancara dengan ust Alwan pada hal. 183.

53 Menurut peneliti alangkah baiknya suatu saat ada penelitian lebih lanjut mengenai Studi komparatif Metode tarjih antara Muhammadiyah dan HTI.

54 Majalah al-Wa'ie No.55, Edisi khusus Maret 2005. 44; Abdul Malik, wawancara (Malang, 9 Desember 2009)
}

damentalis lainnya seperti salafi, Muhammadiyah bahkan Persis. Ketiga ormas/harakah yang peneliti sebutkan secara tegas menolak taqlid, sedangkan HTI tidak melarang aktivisnya untuk taklid. Sikap ini sangat berguna untuk meminimalisir perpecahan internal organisasi sebagaimana yang pernah terjadi di dalam tubuh Masyumi.

Terakhir, hukum-hukum yang berkaitan dengan ritual ibadah, yang diadopsi oleh HTI hanya seputar ibadah yang berkaitan dengan kesatuan umat muslim dan penampakan syiar keagamaan seperti shaum ramadhan, shalat ied, zakat dan jihad ${ }^{55}$ Di luar itu, pengadopsian hukum tertentu dalam masalah ibadah akan menimbulkan kesempitan (haraj) bagi kaum Muslimin, sementara haraj itu tidak boleh ada dalam masalah agama. ${ }^{56}$

\section{Kesimpulan}

Dari hasil penelitian serta analisisnya, maka dapat ditarik kesimpulan, bahwa metode ijtihad aktivis HTI dalam bidang politik diawali dengan fahmul waqi'dan fahmul nash. Kemudian berijtihad memakai metode yang dirumuskan HT (ijtihad manhaji). Kalau permasalahan lama, cukup mengambil rujukan (aplikatif) dalam kitab-kitab HT seperti sistem pemerintahan dalam Islam, dan muqaddimah dustur. Tidak merujuk pada teks kitabnya tapi langsung ke nashnya. Sehingga ijtihadnya tidak akan menyalahi apa yang sudah digariskan dalam buku-buku hizb. Metode ijtihad dalam bidang ibadah diserahkan kepada masing-masing individu. HTI tidak akan mengintervensi atau campur tangan. Hal ini bisa dipahami bahwa HTI tidak memiliki buku-buku pegangan resmi yang mengatur tentang ritual ibadah. Dalam perkara yang sangat luas, para aktivis HTI menggunakan kitab-kitab dari berbagai mazhab dan kitab-kitab fiqh kontemporer. Permasalahan lama cukup mentarjih dari berbagai kitab fiqh. Petinggi HTI kota Malang dalam persoalan ritual ibadah menginginkan agar setiap anggota HTI idealnya memakai dalil terkuat (metode tarjih). Apabila tidak bisa mentarjih sendiri, bermazhab atau bahasa lainnya taklid pun tidak dilarang. Asal kepada mujtahid yang dipercayai kadar keilmuwannya.

\footnotetext{
55 Contoh yang masalah ritual ibadah yang pernah diadopsi oleh HTI adalah Sholat ied berdasarkan rukyatul global. Sebagian besar lainnya ada yang diatur secara tegas dalam buku "Sistem pergaulan dalam Islam", diantaranya diatur: Muslimah tidak wajib menutup wajahnya dengan cadar, larangan bertabaruj, wanita-wanita yang haram dinikahi, poligami, Hukum Azl, kewajiban pemisahan antara pria dan wanita dalam pergaulan seharihari.

56 Ibid.
} 


\section{Saran}

Setelah mengamati dan memahami penelitian ini, ada hal yang perlu diperhatikan, diantaranya: aktivis HTI janganlah membatasi penggunaan dalildalil hukum hanya pada Qur'an, Sunnah, Ijma' Sahabat dan Qiyas. Tetapi seharusnya juga menggunakan dalil-dalil seperti Istihsan, Mazhab shahabi, Mashlahah Mursalah, 'Urf. Gunakanlah dalil-dalil tersebut sesuai kebutuhan dan sepanjang tidak bertentangan dengan nash. HTI sebagai organisasi yang mengharuskan kadernya berkomitmen dengan hukum syara, sebaiknya juga menunjukkan buktinya nyata dalam berijtihad untuk merujuk langsung kepada al-Qur'an dan Sunnah. Jangan sampai komitmen tersebut hanya sebatas retorika belaka. Peranan HTI dalam menjawab problematika umat dengan cara berijtihad, sepertinya kurang dirasakan keberadaannya oleh publik dikarenakan mereka

\section{Daftar Pustaka}

Abdurahman, A Said Aqil Humam. 2004. Hukum Islam Seputar. Bogor: al-Azhar Press.

Abdurrahman, Asjmuni. 2005. Manhaj Tarjih Muhammadiyah: Metodologi dan Aplikasi. Yogyakarta: Pustaka Pelajar, 2007. Pokokpokok Majelis Tarjih Muhammadiyah.

Ahmad, Fadh dkk. 2009. Istinbath Hukum Persis. Malang 2009. Makalah tugas mata kuliah Fatwa dan Yurisprudensi, tidak diterbitkan.

Ahnaf, Moh Iqbal. 2004. "MMI dan HTI: Image of The Others," dalam A.Maftuh Gabriel, Negara tuhan: The Thematic Ensiklopedia. Jogjakarta: SR-Ins Publishing.

Al-Wakil, Muhammad Sayyid. 2005. Wajah Dunia Islam. Jakarta: Pustaka Al-Kautsar.

An-Nabhani, Taqiyuddin. 2003. Hakekat berfikir. Bogor: Pustaka Thariqul Izzah.

An-Nabhani, Taqiyuddin. 2007. Mafahim Hizbut Tahrir: Edisi Mu'tamadah. Jakarta: Hizbut Tahrir Indonesia.

An-Nabhani, Taqiyudin. 2007. Syakhsiyah Islam jilid 1. Jakarta: Hizbut Tahrir Indonesia.

Arifin, Syamsul. 2005. Ideologi dan Praksis Gerakan Kaum Fundamentalis: Pengalaman Hizbut Tahrir Indonesia. Malang: UMM Press.

Arifin, Syamsul. 2005. Ideologi dan Praksis Gerakan Kaum Fundamentalis: Pengalaman Hizbut Tahrir Indonesia. Malang: UMM Press.

Aziz, Abdul. 2006. Gerakan Islam Kontemporer di lebih kental aktivitas dakwah dan politiknya dalam memperjuangkan kembalinya Khilafah Islamiyah. Ditambah lagi belum memiliki lembaga fatwa seperti PKS, Muhammadiyah, NU dan Persis. Oleh karena itu, HTI hendaknya segera membentuk Lembaga Fatwa untuk merespon perkembangan zaman dengan permasalahan yang kian pelik. Di bandingkan dengan Ikhwanul Muslimin, NU dan Muhammadiyyah. Hizbut tahrir hingga kini belum memberikan inovasi dalam metode ijtihad yang ideal bagi umat Islam. Janganlah solusi dari semua problematika umat seperti: Syirik, Khurafat, Bid'ah, aliran sesat, Kristenisasi, Liberalisme, kemiskinan, kebodohan, kebobrokan moral hanya bisa terselesaikan bila kita memilih seorang Khalifah. Seakan-akan Islam dapat terepresentasikan dalam kata "Khilafah" atau "Khalifah".

Indonesia. Jakarta: Diva Pustaka.

Bisri, Cik Hasan. 2004. Pilar-Pilar Penelitian Hukum Islam dan Pranata Sosial. Jakarta: Rajawali Press.

Corbin, Juliet dkk. 1997. Dasar-Dasar Penelitan Kualitatif. Surabaya: Bina Ilmu.

Dahlan, Abdul Aziz, et. al. 1996. Ensiklopedi Hukum Islam jilid 2. Jakarta : Ichtiar Baru van Hoeve.

Fatah, Rohadi Abdul. 2006. Analisis Fatwa Keagamaan Dalam Fikih Islam. Jakarta: Bumi Aksara.

Handrianto, Budi. 2007. 50 Tokoh Islam Liberal Indonesia. Jakarta: Hujjah Press.

Hasan, M. Tholchah. 2000. Diskursus Islam Kontemporer. Jakarta: Listafariska Putra.

Hassan, Ahmad. 2005. Kumpulan Risalah A. Hassan. Bangil: Pustaka Elbina.

Hawari, Muhammad. 2005. Reideologi Islam: Membumikan Islam Sebagai Sistem. Bogor: alAzhar Press.

Hosen, Ibrahim. 1988. Memecahkan Permasalahan Hukum Baru, dalam Ijtihad dalam Sorotan, ed. Haidar Bagir dan Syafiq Basri . Bandung: Mizan.

Idem, 2007. Syakhsiyah Islam jilid 1. Jakarta: Hizbut Tahrir Indinesia.

Idem. 2004. Jejak Tokoh Islam dalam Kristenisasi. Jakarta: Darul Falah.

Idem. 2009. Islam dan al-Qur'an pun di Serang. Jakarta: Pustaka Nahi Munkar. 
Iqbal, Muhammad. 2002. Rekonstruksi Pemikiran Agama Dalam Islam. Yogyakarta: Lazuardi.

Iskandar. 2008. Metodologi Penelitian Pendidikan Dan Sosial "Kualitatif \& Kuantitatif. Jakarta: GP Pres.

Jaiz, Hartono Ahmad. 2005. Ada Pemurtadan di IAIN. Jakarta: Pustaka al-Kautsar.

Jumantoro, Totok.2005. Kamus Ilmu Ushul Fiqh. Jakarta: Amzah.

Kajian islam ideologis. "Kemaslahatan Dalam Perspektif Akal dan Wahyu” ( 20 Mei 2007).

Khalil, Atha' bin. 2003. Ushul Fiqih: Kajian Ushul Fiqih Mudah dan Praktis. Bogor: Pustaka Thariqul Izzah.

Latif, Yudi. 2005. Intelegensia Muslim dan Kuasa: Geneakologi Intelegensia Muslim Indonesia Abad ke-20. Bandung: Mizan.

Ma'arif, Syafi'i. 1995. Metode Ijtihad Majelis Tarjih Muhammadiyah. Jakarta: TP.

Majalah al-wa'ie No 55 Tahun V Edisi Khusus Maret 2005.

Moleong, Lexi J. 2005. Metode Penelitian Kualitatif, edisi revisi. Bandung: Remaja Rosda Karya.

Mubarak, Zaki. 2008. Geneakologi Islam Radikal di Indonesia: Gerakan, Pemikiran dan Prospek Demokrasi. Jakarta: LP3ES.

Mubarok, Jaih. 2005. Ijtihad Kemanusiaan di Indonesia. Bandung: Pustaka Bani Quraisy.

Nur, Saifudin. 2007. Ilmu Figh: Suatu Pengantar Komprehensif Kepada Hukum Islam. Bandung: Tafakur.

Qardhawi, Yusuf. 2004. Ijtihad Kontemporer: Kode Etik dan Berbagai Penyimpangan. Surabaya: Risalah Gusti.

Rahmat, M. Imdadun. 2005. Arus Baru Islam Radikal. Jakarta: Erlangga.

Rakhmat, Imdadun. 2008. Ideologi Politik PKS: Dari Masjid Kampus ke Gedung Parlemen. Yogyakarta: LKIS.
Ramadla, Syamsudin. 2004. Meluruskan Makna Ijtihad, dalam al-Wa'ie No. 48 Tahun IV, 1-31 Agustus.

Romly, Lilis. 2006. Islam Yes Partai Islam Yes. Yogyakarta: Pustaka Pelajar.

Rosyada, Dede. 1999. Metode Kajian Hukum Dewan Hisbah Persis. Jakarta: Logos wacana Ilmu.

Salim, Agus. 1982-2000. "The Rise of Hizbut Tahrir Indonesia: A Mobilization from Campuses to the streets (1982-2000)" dalam Yusuf Rahmad, Islam and Society in Contemporary Indonesia. Jakarta: CIDA-PPs UIN Syarif Hidayatullah.

Sejahtera, Dewan Syariah Pusat PK. 2005. Ittijah Fiqih Dewan syariah PKS. Jakarta: Dewan Sayriah Pusat PKS.

Sejahtera, Dewan Syariah Pusat PK. 2006. FatwaFatwa Dewan Syariah Partai Keadilan Sejahtera. Bandung: Harakatuna Publishing.

Sumbulah, Umi. 2007. Gerakan fundamentalisme Islam di Malang studi atas Hizbut Tahrir, Majelis Mujahidin, dan Arimatea. Istiqro'. Vo 1 6 No. 1. Jakarta: Departemen Agama.

Syafe'i, Rachmat.1999. Ilmu Ushul Fiqh. Bandung: Pustaka Setia.

Syarifudin, Amir. 2001. Ushul Fiqih jilid 2. Jakarta: Logos.

Yusuf , M. Yunan (ed). 2005. Ensiklopedi Muhammadiyah. Jakarta : Rajawali Pers.

Yusuf, M. Yunan (ed). 2005. Ensiklopedi Muhammadiyah. Jakarta: Rajawali Pers.

Zahrah, Muhammad Abu. 1994. Ushul Fiqh. Jakarta: Pustaka Firdaus.

Zahro, Ahmad. 2004. Tradisi Intelektual NU. Yogyakarta: Lkis.

Zein, M. Satria Efenndi, M, 2005. Ushul Fiqh. Jakarta: Kencana.

Zuhdi, Masjfuk.1981. Ijtihad dan Problematika. Surabaya : Bina Ilmu. 